\title{
The potential applications of Apolipoprotein E in personalized medicine
}

\author{
Sylvia Villeneuve ${ }^{1,2}$, Diane Brisson ${ }^{1}$, Natalie L. Marchant ${ }^{3}$ and Daniel Gaudet $^{1 \text { * }}$ \\ 1 Department of Medicine, ECOGENE-21 and Lipid Clinic, Chicoutimi Hospital, Université de Montréal, Chicoutimi, OC, Canada \\ 2 Helen Wills Neuroscience Institute, University of California, Berkeley, CA, USA \\ ${ }^{3}$ Department of Old Age Psychiatry, Institute of Psychiatry, King's College London, London, UK
}

Edited by:

Paula I. Moreira, University of

Coimbra, Portugal

Reviewed by:

Ya Ke, The Chinese University of

Hong Kong, Hong Kong

André Karch, Helmholtz Centre for

Infection Research, Germany

*Correspondence:

Daniel Gaudet, ECOGENE-21,

Chicoutimi Hospital, Université de

Montréal, 305 St.-Vallier, Chicoutimi,

OC G7H 5H6, Canada

e-mail:daniel.gaudet@umontreal.ca
Personalized medicine uses various individual characteristics to guide medical decisions. Apolipoprotein (ApoE), the most studied polymorphism in humans, has been associated with several diseases. The purpose of this review is to elucidate the potential role of ApoE polymorphisms in personalized medicine, with a specific focus on neurodegenerative diseases, by giving an overview of its influence on disease risk assessment, diagnosis, prognosis, and therapy. This review is not a systematic inventory of the literature, but rather a summary and discussion of novel, influential and promising works in the field of ApoE research that could be valuable for personalized medicine. Empirical evidence suggests that ApoE genotype informs pre-symptomatic risk for a wide variety of diseases, is valuable for the diagnosis of type III dysbetalipoproteinemia, increases risk of dementia in neurodegenerative diseases, and is associated with a poor prognosis following acute brain damage. ApoE status appears to influence the efficacy of certain drugs, outcome of clinical trials, and might also give insight into disease prevention. Assessing ApoE genotype might therefore help to guide medical decisions in clinical practice.

Keywords: ApoE, cardiovascular diseases, Alzheimer disease, neurodegenerative diseases, risk, diagnosis, prognosis, treatment

\section{INTRODUCTION}

\section{PERSONALIZED MEDICINE AND GENETIC}

Personalized medicine refers to medical care that uses individual characteristics, such as family and personal history, gene, protein, or environmental information to facilitate a global analysis of individual risk evaluation, diagnosis and prognosis, and improve therapeutic and preventive approaches for patients (Offit, 2011). Personalized medicine would therefore guide medical decisions. Even though the practice of personalized medicine is not new, there is an increasing enthusiasm in this approach which can be attributed to the exploding field of genetic research.

Apolipoprotein (ApoE) is a protein that is well known for its key roles in the transport of cholesterol and other lipids in blood circulation and central nervous system (CNS). Since its identification in 1973 (Shore and Shore, 1973), ApoE has become one of the most widely studied gene variants, not only for cardiovascular disorders but also in relation to several other medical conditions such as neurodegenerative and autoimmune diseases (Mahley, 1988; Mahley et al., 2009; Verghese et al., 2011). Given its broad biological role, ApoE may therefore become a major variable of preventive medicine. This review aims to summarize the role of ApoE in components of personalized medicine, including the individual risk prediction, diagnosis, prognosis, and treatment of associated diseases. This review is intended to summarize and discuss novel, influential and promising works in the field with a specific, but not exclusive, focus on neurodegenerative diseases.

\section{APOLIPOPROTEIN E BASIC STRUCTURES AND FUNCTION}

ApoE includes three common isoforms (ApoE2, ApoE3, ApoE4), coded by three codominant alleles (e2, e3, e4). Hence, six phenotypes commonly exist in the general population, three homozygous (ApoE2/2, ApoE3/3, and ApoE4/4) and three heterozygous (ApoE2/3, ApoE2/4, and ApoE3/4). ApoE2 and ApoE4 differ from ApoE3 by a single amino acid substitution. While ApoE3 contains cysteine at position 112 and arginine at position 158, the arginine is substituted by a cysteine in ApoE2 carriers and the cysteine is substituted by an arginine in ApoE4 carriers (Weisgraber et al., 1982; Mahley, 1988). This arginine substitution results in an interaction between ApoE4 amino- and carboxylterminal domains, known as "domain interaction" (Mahley and Huang, 2009). The structural difference due to domain interaction is believed to play a role in the altered function of ApoeE4.

ApoE is synthesized predominantly in the liver but is also found in the brain, spleen, lung, kidney, ovary, testis, peripheral nerves and muscular tissues (Zhang et al., 2011). In the brain, ApoE is produced by astrocytes and, to a minor extent, by microglia (Pitas et al., 1987; Grehan et al., 2001), and can also be produced by neurons in response to neuronal injury or stress (Mahley and Huang, 2012a). ApoE's principal known function is to transport cholesterol and other lipids in blood circulation and the CNS by binding to ApoE receptors on their cell surface (Mahley, 1988). ApoE is also essential to maintain the structural integrity of lipoproteins, stabilize, and solubilize 
liproproteins in the blood, and to serve as cofactors in enzymatic reaction (Eichner et al., 2002). In the brain, cholesterol plays a crucial role in myelin production and is an essential component of membrane sheaths, brain development, neuronal maintenance, neuronal repair, and long-term synaptic plasticity (Mauch et al., 2001; Bu, 2009; Mahley et al., 2009; Leduc et al., 2011).

\section{RISK ASSESSMENT}

Because of its key role in the regulation of lipid metabolism ApoE was first recognized for its role in cardiovascular diseases (CVD). While the ApoE3 isoform is not associated with an increased risk of CVD, the ApoE4 isoform is a major risk factor for CVD, such as coronary heart disease, arrhythmias, and stroke (Lahoz et al., 2001; Eichner et al., 2002; Song et al., 2004; Mahley et al., 2009). ApoE2 has a more ambiguous relationship with CVD as it has been associated with both an increased (Mahley et al., 1999; Lahoz et al., 2001) and reduced (Bennet et al., 2007) risk of CVD. This duality found in the ApoE2 isoform suggests that the adverse or beneficial impact of ApoE2, and potentially ApoE4, on disease risk is influenced by it interaction with other genetic or environmental factors (Lahoz et al., 2001; Elosua et al., 2003; Mahley et al., 2009).

It is now well recognized that ApoE is also associated with a variety of other diseases. ApoE4 for instance is the most important genetic risk factor for late onset Alzheimer Disease (AD) (Poirier et al., 1993; Leduc et al., 2011; Verghese et al., 2011) with ApoE4 carriers having a 4 to 12 -fold increased risk of developing AD when compared to non-carriers (Corder et al., 1993, 1994; Bertram and Tanzi, 2008; Mahley and Huang, 2012a). The ApoE2 isoform on the other hand is protective against $\mathrm{AD}$ (Corder et al., $1993,1994)$. How these isoforms differently affect the risk of AD is not fully understood. Several mechanisms have been implicated. One potential mechanism is via accumulation and/or clearance of amyloid- $\beta$ ( $\mathrm{A} \beta$, a hallmark of $\mathrm{AD}$ ) from the brain because ApoE4 has been associated with greater $A \beta$ burden (Strittmatter et al., 1993; Ye et al., 2005; Drzezga et al., 2009) and ApoE2 with lower A $\beta$ burden (Jiang et al., 2008; Morris et al., 2010). It is well established that ApoE binds directly to the $A \beta$ peptide. Compared to the other isoforms, ApoE4 binds to $A \beta$ with lower affinity, which might result in less efficient clearing of $A \beta$ through the cell surface (Ladu et al., 1994; Yang et al., 1999; Tokuda et al., 2000). In the same line, ApoE4 is associated with slower transport of $A \beta$ across the blood-brain barrier (BBB), causing greater $A \beta$ retention in mice brains (Deane et al., 2008). ApoE4 is also associated with $\mathrm{BBB}$ dysfunction, which might lead to $\mathrm{A} \beta$ accumulation, and also to a reduction in cerebral blood flow and hypoxia, two conditions that enhance brain vulnerability (Zlokovic, 2011). While several routes exist for the clearance of $\mathrm{A} \beta$, clearance directly into the blood seems to be the predominant pathway in the human brain (Bell and Zlokovic, 2009; Bell et al., 2012). Accordingly, vessel wall thickness and reduced cerebral blood flow may result in $A \beta$ accumulation. Supporting this idea, ApoE4 carriers are known to have higher accumulation of $A \beta$ in cerebral blood vessels, a condition known as cerebral amyloid angiopathy (CAA) (Verghese et al., 2011). ApoE4 is also associated with greater neuronal inflammation (Grainger et al., 2004; Guo et al., 2004; Kim et al., 2009; Leduc et al., 2011) and less efficient neuronal repair
(Mauch et al., 2001; Bu, 2009; Mahley et al., 2009; Leduc et al., 2011), two other conditions that might influence the risk of AD. Finally, in response to neuronal injury, neuron-ApoE4 production can generate neurotoxic fragments that exacerbate neuronal toxicity, increase tau phosphorylation, NFT formation, neuronal mitochondrial dysfunction, and decrease GABAergic interneuron selectivity (Mahley and Huang, 2012a; Liu et al., 2013).

The association of ApoE with other neurodegenerative diseases is less clear. Recent meta analyses suggest that ApoE4 carriers might be more susceptible to Creutzfeldt-Jakob disease (Wei et al., 2014). ApoE2 in turn might increase the risk of age-related macular degeneration (Leduc et al., 2011) and Parkinson disease (Huang et al., 2004) highlighting again the ambiguous role of ApoE2.

As it can be seen in Table 1, the impact of ApoE goes far beyond the boundary of CVD and neurodegenerative diseases. Links have been suggested for instance between ApoE4 and the susceptibility to malaria, viral infections such as herpes simplex virus (HSV), human immunodeficiency virus (HIV) (Mahley et al., 2009; Zhang et al., 2011), cancer (Porrata-Doria et al., 2010; Kulminski et al., 2011; Saadat, 2012), and gallbladder stone disease (Xue et al., 2012). Even if these last associations are not always consistent between studies, all together they suggest that ApoE influences the risk of a variety of diseases which supports the idea that ApoE influences human health via multiple pathways.

At present the utility of determining ApoE genotype in everyday practice is questionable for two reasons: ApoE is principally a risk factor and not a causal factor, and inconsistencies remain in the literature, particularly for diseases other than CVD and AD. Understanding the cause of these inconsistencies, or why some persons do not develop a specific disease, might however yield great potential for disease prevention. Indeed, for some diseases, ApoE might only have a detrimental effect under specific circumstances or when interacting with other factors. While ApoE alone might therefore not be useful to assess risk of developing a specific disease, it could be included in an integrated risk evaluation metric. The association between the e 4 allele and a poor vascular health for instance seems to be stronger in the presence of life stress factors and habits such as obesity, alcohol consumption, and smoking (Corella et al., 2001; Djousse et al., 2002; Zeng et al., 2011). Indeed weight gain and obesity appear to have a particularly severe effect on ApoE4 carriers, and have been associated with increases in triglycerides, $\beta$ lipoprotein (Gueguen et al., 1989), total insulin and LDL cholesterol levels (Marques-Vidal et al., 2003). If clinicians possessed this knowledge and ApoE genotype information, they could provide more patient-specific treatment advice that would particularly help ApoE4 carriers reduce their risk of CVD. Another example would be the interaction between ApoE and lifestyle on the risk of AD. Increased physical activities and good vascular health appear to reduce the negative effect of ApoE4 on $\mathrm{A} \beta$ and $\mathrm{AD}$ (Niti et al., 2008; Ferrari et al., 2013). Physical activity also reduces the rate of hippocampal atrophy in ApoE4 carriers, an effect that was not observed in noncarriers (Smith et al., 2014). The hippocampus is a key structure for episodic memory formation (Villeneuve and Belleville, 2012), and is particularly sensitive to $\mathrm{AD}$. Lifetime cognitive activity also seems to reduce the negative impact of ApoE on $A \beta$ burden, since 
Table 1 | Association of ApoE to pre-symptomatic risk, prognosis, and response to treatment.

\begin{tabular}{lccc}
\hline \multicolumn{1}{c}{ Phenotype } & Risk & Prognosis & Treatment \\
\hline HYPERLIPIDEMIA (Mahley, 1988; Mahley et al., 1999; Maitland-Van Der Zee et al., 2003; Nieminen et al., 2008; Dergunov, 2011) \\
$\begin{array}{llcl}\text { Familial hyperlipidemia and } & \text { E2 } & (-) & \text { Highest response to lipid-lowering therapy } \\
\text { hypercholesterolemia } & \text { E4 } & + & \text { Lowest response to lipid-lowering therapy } \\
& & & \text { Lowest compliance to treatment } \\
& \text { Highest response to low fat diet }\end{array}$
\end{tabular}

\begin{tabular}{ll}
\hline Familial dysbetalipoproteinemia & E2 \\
& E4
\end{tabular}

CARDIOVASCULAR DISEASES (Lahoz et al., 2001; Eichner et al., 2002; Masson et al., 2003; Song et al., 2004;

Martinez-Gonzalez and Sudlow, 2006; Stehle et al., 2008; Mahley et al., 2009; Guo et al., 2011; Khan et al., 2013; Rannikmae et al., 2013)

Stroke

E2

E4 (+) Worst prognosis

$\uparrow$ Risk of death*

\begin{tabular}{llll}
\hline Coronary heart disease & E2 & $(-)$ & \\
& E4 & + & $\uparrow$ Risk of death \\
\hline Cerebral amyloid angiopathy & E2 & $\begin{array}{l}\uparrow \text { Risk hemorrhage } \\
\text { (CAA) }\end{array}$ \\
& E4 Risk hemorrhage \\
& & $\begin{array}{l}\uparrow \text { Severity } \\
\text { Risk death }\end{array}$
\end{tabular}

NEURODEGENERATIVE DISEASES (Poirier et al., 1993; De La Fuente-Fernandez et al., 1999; Bedlack et al., 2000; Leduc et al., 2011; Verghese et al., 2011; Panza et al., 2012; Yin et al., 2012)

Alzheimer disease (AD)

E2 $\quad-\quad$ Later onset

E4 $+\quad$ Earlier onset

$\uparrow$ Neuropsychiatric symptoms

Cognition: Lowest response or no improvement in persons with dementia but higher response in persons with mild cognitive impairment Biomarkers (amyloid and CSF tau): higher response in persons with dementia

\begin{tabular}{|c|c|c|c|c|}
\hline $\begin{array}{l}\text { Vascular disease-associated } \\
\text { cognitive impairment }\end{array}$ & $\begin{array}{l}\text { E2 } \\
\text { E4 }\end{array}$ & & $\uparrow$ Risk dementia & \\
\hline Lewy body disease & E2 & & & \\
\hline \multirow[t]{2}{*}{ Pick's disease } & E2 & & & \\
\hline & E4 & & $\begin{array}{l}\text { Earlier onset } \\
\uparrow \text { Risk dementia }\end{array}$ & \\
\hline \multirow[t]{2}{*}{ Corticobasal degeneration } & E2 & & & \\
\hline & E4 & & $\uparrow$ Risk dementia & \\
\hline \multirow[t]{2}{*}{ Down'syndrome } & E2 & & & \\
\hline & E4 & & $\begin{array}{l}\text { Faster progression } \\
\uparrow \text { Risk dementia }\end{array}$ & \\
\hline \multirow{2}{*}{$\begin{array}{l}\text { Amyotrophic lateral sclerosis } \\
\text { (ALS) }\end{array}$} & E2 & & Later onset & \\
\hline & E4 & & $\begin{array}{l}\text { Earlier onset } \\
\text { Worst prognosis }\end{array}$ & \\
\hline \multirow[t]{2}{*}{ Age-related macular degeneration } & E2 & $(+)$ & Earlier onset & \\
\hline & E4 & $(-)$ & Later onset & \\
\hline
\end{tabular}




\begin{tabular}{|c|c|c|c|c|}
\hline & Phenotype & Risk & Prognosis & Treatment \\
\hline \multicolumn{5}{|c|}{$\begin{array}{l}\text { AUTOIMMUNE DISEASES (Corder et al., 1998; Roselaar and Daugherty, 1998; De Bont et al., 1999; Mahley et al., 2009; Vitek et al., 2009; } \\
\text { Kuhlmann et al., 2010; Zhang et al., 2011) }\end{array}$} \\
\hline Human immunodeficiency virus & $\mathrm{E} 2$ & & & ( $\uparrow$ Risk hypertriglyceridemia) \\
\hline$(\mathrm{HIV})$ & E4 & $(+)$ & $\begin{array}{l}\uparrow \text { Risk dementia } \\
\uparrow \text { Risk Peripheral neuropathy } \\
\uparrow \text { Risk AIDS }\end{array}$ & ( $\uparrow$ Risk hypertriglyceridemia) \\
\hline
\end{tabular}

\begin{tabular}{|c|c|c|c|}
\hline Acquired immunodeficiency & E2 & & \\
\hline syndrome (AIDS) & E4 & + & Worst prognosis \\
\hline Hepatitis C virus & E2 & & $\begin{array}{l}\text { E3 and E2: } \uparrow \text { Risk chronic } \\
\text { infection }\end{array}$ \\
\hline
\end{tabular}

E4

(Lowest response to antiviral therapy)

OTHER [TRAUMATIC BRAIN INJURY (Lichtman et al., 2000; Chamelian et al., 2004; Crawford et al., 2009; Hiekkanen et al., 2009;

Ponsford et al., 2011); DIABETES MELLITUS (Tsuzuki et al., 1998; Bedlack et al., 2003; Saito et al., 2004; Yin et al., 2013); CANCER

(Ahles et al., 2003; Porrata-Doria et al., 2010; Kulminski et al., 2011; Saadat, 2012); DEPRESSION (Irie et al., 2008; Kim et al., 2010, 2011;

Meng and D'Arcy, 2013)]

Traumatic brain injury $\quad$ E2

E4 Worst prognosis

Diabetes mellitus E2

E4 $\uparrow$ Risk diabetic neuropathy Best response to low fat diet

Cancer E2

E4 (+) (E4: $\uparrow$ side effect following chemotherapy)

\begin{tabular}{lll}
\hline Depression & E2 & \\
& E4 & $\uparrow$ Risk dementia
\end{tabular}

Creutzfeldt-Jakob disease, gallbladder stone disease, Huntington's disease, inclusion-body myositis, cerebral palsy, progressive supranuclear palsy, temporal lobe epilepsy multiple system atrophy, multiple sclerosis, frontotemporal dementia, malaria and herpes simplex virus need further exploration (Bu, 2009; Leduc et al., 2011; Verghese et al., 2011; Xue et al., 2012; Yin et al., 2012; Rubino et al., 2013; Wei et al., 2014). *In subarachnoid hemorrhage and intracerebral hemorrhage stroke; +, increased risk; -, decreased risk; (parentheses), limited, or conflicting results exist.

ApoE4 carriers that report high lifetime cognitive activity have similar A $\beta$ brain burden than non-carriers (Wirth et al., 2014). Incorporating these findings into medical practice would suggest that physical and cognitive activity could be used as preventive activities to reduce the risk of $\mathrm{AD}$ in ApoE4 carriers. With no current treatment for $\mathrm{AD}$, and with ApoE being the main risk factor for this disease, better understanding of the factors that interact with ApoE-related risk to postpone the development of the disease is needed given their potential implication in preventive medicine. Understanding these interactions might also be valuable to guide new treatment developments.

\section{DIAGNOSIS}

As mentioned previously, although knowing ApoE status is valuable to assess pre-symptomatic risk for disease, it is rarely sufficient to make a diagnosis. Type III dysbetalipoproteinemia diagnosis, a rare inherited disorder caused by ApoE (commonly ApoE2) defective binding to lipoprotein receptor, is however an exception (Mahley et al., 1999). Type III is mainly-but not exclusively_-diagnosed among individuals who are homozygous for the apolipoprotein e2 allele (ApoE2/2). Therefore, assessment of ApoE genotype plays a critical role in type III dysbetalipoproteinemia diagnosis. However, only a minority of ApoE2/2 carriers develops this disease. Furthermore, even in subjects who develop the disease, the majority remain normolipidemic for decades, particularly in the absence of additional primary or secondary dyslipidemic factors. This last point supports the value of knowing the ApoE status in patients with a family history of type III dysbetalipoproteinemia because by controlling, or preventing, other dyslipidemic factors it is may be possible to postpone the expression of the disease.

\section{PROGNOSIS}

In addition to affecting the risk for several diseases, ApoE can influence the pattern of their progression. For instance in several types of dementia, ApoE4 has been related to earlier onset as well as higher risk of neuropsychiatric symptoms (Leduc et al., 2011; Panza et al., 2012). An obvious example is in AD were ApoE4 carriers develop dementia 8-20 years earlier then non-carriers (Corder et al., 1993; Mahley and Huang, 2012a). ApoE4 is also associated with an increased risk of dementia in Parkinson disease, Lewy body disease, Pick's disease, vascular diseases, Down's syndrome, corticobasal degeneration, and HIV (Mahley et al., 2009; Leduc et al., 2011; Verghese et al., 2011). While ApoeE4 does not appear to increase risk for depression per se (Mauricio et al., 2000; Blazer et al., 2002), it has been associated with an 
increased risk for dementia in individuals with depression (Irie et al., 2008; Kim et al., 2010, 2011; Meng and D'Arcy, 2013). Except for $\mathrm{AD}$, these findings suggest that ApoE might not be associated with the disease pathology itself, but that ApoE4 makes the brain less resiliant to neurodegenerative processes. Knowing the ApoE genotype of a person with a neurodegenerative disease might therefore give insight on the risk of developing dementia. Regular cognitive evaluations might be appropriate in such cases.

The interaction between neurodegenerative diseases such as $\mathrm{AD}$ and ApoE genotype on rate of cognitive decline have been extensively studied, but the findings are inconsistant. While some studies suggest that ApoE4 AD carriers have a faster rate of cognitive decline (Craft et al., 1998; Martins et al., 2005; Schmidt et al., 2012), others suggest no association (Growdon et al., 1996; Kleiman et al., 2006). It has even been proposed that non-carriers present a slightly different, and more agressive, form of $\mathrm{AD}$ and that the latter group shows a faster progression than the ApoE4 carriers (Stern et al., 1997). In regard to persons with mild cognitive impairment, the presence of an 44 allele is associated with an increased risk of progression to dementia (Mosconi et al., 2004; Petersen et al., 2005; Vos et al., 2013). In such cases, knowing the ApoE status seems to give useful information about the prognosis. Because mild cognitive impairment can be caused by several conditions such as AD, vascular disease, Parkinson disease, and depression (Gauthier et al., 2006; Villeneuve et al., 2011a,b, 2012), knowing the ApoE status could also give insight about the source of disease. Indeed, as mentioned previously ApoE4 is the strongest genetic risk factor for $\mathrm{AD}$ and ApoE4 carriers often have higher $A \beta$ burden. Accordingly, ApoE4 carriers with mild cognitive impairment are usually considered at increased risk of $\mathrm{AD}$ (Petersen et al., 2005).

Knowledge of ApoE genotype also provides valuable information about recovery prognosis after an acute event such as stroke (Martinez-Gonzalez and Sudlow, 2006; Guo et al., 2011), delirium (Adamis et al., 2007), or traumatic brain injury (TBI) (Lichtman et al., 2000; Crawford et al., 2009; Mahley et al., 2009; Ponsford et al., 2011). In all these cases, ApoE4 carriers show a worse long-term outcome than ApoE3 carriers, and even sometimes higher risk of death. The presence of an e4 allele has also been associated with greater cognitive decline in older stroke patients (Ballard et al., 2004). A predominant hypothesis in the literature is that this poor outcome is caused by a lack of reparative capacity of ApoE4 (Crawford et al., 2009; Ponsford et al., 2011). Given this knowledge, after an adverse event ApoE4 carriers should have a closer follow-up and older adults should be assessed for associated cognitive deficits.

The value of knowing the ApoE status in the prediction of disease prognosis is not restricted to neurodegenerative diseases or brain integrity as can be seen in Table 1. ApoE4 patients affected by HIV are for instance at higher risk of developing peripheral neuropathy and acquired immunodeficiency syndrome (AIDS). Higher cerebrospinal fluid (CSF) ApoE levels have also been associated with higher cognitive impairment in patients affected by HIV (Andres et al., 2011), a finding that was also present in persons with mild cognitive impairment (Song et al., 2012) but not in $\mathrm{AD}$ patients (Schmidt et al., 2014). In addition, ApoE4/4 carriers suffering from AIDS have accelerated disease progression and increased risk of death (Corder et al., 1998; Zhang et al., 2011). These data suggest that, in regard to many diseases, a closer follow-up is needed in ApoE4 carriers since this genotype is associated with worst prognosis.

\section{TREATMENT}

\section{ApoE AND DOSE RESPONSE}

It is well known that genetics influence drug absorption, distribution, and metabolism, leading to differences in dose responses and side effects. Several reports suggest that ApoE alleles influence therapy efficiency for dyslipidemias (Brisson et al., 2002; Nieminen et al., 2008; Dergunov, 2011). In fact, ApoE genotype is considered the most significant predictor of lipid response to statins and fibrates, two classes of lipid-lowering therapy which act via different mechanisms (Dergunov, 2011). While individuals with ApoE4 seem to have the poorest response to lipid-lowering therapy, individuals with ApoE2 have the highest response (Dergunov, 2011). This result has been shown using different molecules (Ordovas et al., 1995; Nestel et al., 1997; Sanllehy et al., 1998; Ballantyne et al., 2000; Pedro-Botet et al., 2001; Zuccaro et al., 2007) and has been replicated in familial hypercholesterolemia patients (O'Malley and Illingworth, 1990; Carmena et al., 1993). Phenotypic differences in lipid metabolism may help explain these findings (Weisgraber et al., 1982; Mahley, 1988; Dong et al., 1994; Dong and Weisgraber, 1996; Petersen et al., 2005; Hatters et al., 2006).

Assessing ApoE polymorphism might be particularly important in clinical trials. In a Phase IIB clinical trial of an anti-diabetic drug, rosiglitazone, to target mild to moderate $\mathrm{AD}$ patients, the results were inconclusive when patients with and without ApoE4 were pooled together (Risner et al., 2006). However, when ApoE4 carriers were subtracted from the analysis, a significant cognitive improvement was observed in ApoE4 non-carriers (Risner et al., 2006). A recent clinical trial of Bapineuzumab, an anti-amyloid $\beta$ monoclonal antibody, conducted in mild to moderate $\mathrm{AD}$ patients reported reduction in cerebral $\mathrm{A} \beta$ and $\mathrm{CSF}$ phospho-tau concentrations in ApoE4 carriers, but not in noncarriers (Salloway et al., 2014). Turning to the cholinergic system, response profiles of ApoE4 carriers have been mixed in $\mathrm{AD}$ patients with dementia (Poirier et al., 1995; Farlow et al., 1996, 1998; Bizzarro et al., 2005; Choi et al., 2008; Carriere et al., 2009), but non-demented ApoE4 carriers have shown greater cognitive response to the cholinesterase inhibitor, donepezil (Petersen et al., 2005), and to the cholinergic agonist, nicotine (Marchant et al., 2010; Evans et al., 2013). The severity of the disease might therefore also be an important factor to consider when assessing these relationships.

The effect of ApoE on response to treatment in other diseases is not clear and/or research is lacking (Stehle et al., 2008; Carmona et al., 2011; Guerrero et al., 2011). One interseting finding that deserves to be mentioned is that, following chemotherapy, ApoE4 carriers are at increased risk of cognitive deficits (Ahles et al., 2003). In the same line, older ApoE4 carriers are at increased risk of delirium following surgery (Leung et al., 2007). The assessment of ApoE might therefore help guide the choice of treatment or give knowledge about potential side effects. 
In addition to orienting treatment management, a better comprehension of disease interaction with gene variants may eventually help to create new treatments. A novel approach that is getting increasing attention is the potential conversion of ApoE4 into a molecule that is structurally and functionally similar to ApoE3 (or ApoE2). Recent studies that have investigated small molecules to block domain interaction in ApoE4, have largely been successful in preventing the deleterious effects associated with E4 (Mahley and Huang, 2012b; Liu et al., 2013). Other strategies, such as using drugs that promote ApoE levels, increase the ABC 1 expression, increase ApoE receptor 2, or restore brain vascular integrity might also be potential targets (Champagne et al., 2003; $\mathrm{Bu}, 2009$; Liu et al., 2013). Cyclophilin A for instance seems to be a valuable target to offset the negative impact of ApoE4 on BBB and potentially improve, or reverse, microvascular, and cerebral blood flow reduction (Bell et al., 2012). Because neurovascular defects can initiate neuronal dysfunction and neurodegenerative changes, such treatment might be valuable to prevent or slow down neurodegeneration in older adults. As previously mentioned, preventing $\mathrm{BBB}$ breakdown might also have a positive effect on A $\beta$ accumulation (Deane et al., 2008; Bell and Zlokovic, 2009). Even if research on these new therapeutic approaches is not yet accessible in humans, their potential therapeutic implications have already created enthusiasm in the scientific community (Bu, 2009; Ramaswamy and Kordower, 2011; Mahley and Huang, 2012a).

\section{ApoE, NUTRIGENETIC, AND LIFESTYLE}

Interestingly, while ApoE4 carriers are usually least sensitive to statins, they are highly responsive to reduced fat diets. A systematic review conducted in 2003 suggests that ApoE4 carriers tend to show the greatest decrease in LDL-cholesterol and total-cholesterol following dietary changes (Masson et al., 2003). Saito et al. reported similar results in patients with type 2 diabetes after a 14 day reduced fat diet therapy, showing a mean reduction of $15.6 \%$ for LDL-cholesterol and of $16.3 \%$ for total cholesterol in the ApoE3/4 group compared to 0.7 and $6.6 \%$, respectively in the ApoE3/3 group (Saito et al., 2004). Variation in HDL-cholesterol following a diet rich in polyunsaturated fat is unclear (Masson et al., 2003; De Andrade et al., 2010); however, physical activity, particularly in ApoE4 carriers (Bernstein et al., 2002), increases HDL cholesterol (Marrugat et al., 1996; Kokkinos and Fernhall, 1999). These findings are encouraging because they suggest that alternative and/or complementary approaches can be use to control metabolic variation in ApoE4 carriers.

As is well known, the lipid profile of a person has important implications for CVD development. Controlling lipid levels might also have a beneficial effect for $\mathrm{AD}$ prevention. In a recent in vivo study it was shown that increased LDL cholesterol was associated with increased brain A $\beta$ levels (Reed et al., 2014). Higher HDL cholesterol levels have also been found to be protective against atrophy in brain regions vulnerable to $\mathrm{AD}$ (Villeneuve et al., 2014). Therefore, knowing the ApoE genotype of a person might influence the type of treatment proposed, or at least highlights the importance of incorporating lifestyle changes as part of an intervention plan.

\section{ApoE GENOTYPE AND COMPLIANCE TO TREATMENT}

In addition to the drug response dosage, the APOE genotype might influence adherence to treatment, a primary concern in medicine (Maitland-Van Der Zee et al., 2003). Indeed, in a population-based study, Maitland-van der Zee et al. found that subjects with ApoE4/4 genotype had a 2.28-fold increased risk of ending a statin therapy when compared to individuals with the ApoE3/3 genotype (Maitland-Van Der Zee et al., 2003). This risk was predominant among men. Unfortunately, the reasons for discontinuing statin were not explored, however adverse side effects is the principal reason for discontinuing antihyperlipidemic therapy (Andrade et al., 1995). ApoE carriers in the Maitland-Van Der Zee et al. study showed a trend toward higher dosage when compared to the other genotypes, which might have resulted in more severe side effects (Maitland-Van Der Zee et al., 2003). It is also possible that ApoE4 genotype is associated with more side effects independently of dosage as this has been found in other diseases (De La Fuente-Fernandez et al., 1999; Porrata-Doria et al., 2010). The second most frequent reason for ending therapy is therapeutic inefficacy (Andrade et al., 1995). Again, this reason might explain why ApoE4 is associated with an increased risk of drug discontinuation given the well-known lower response of ApoE4 carriers to treatment (Nieminen et al., 2008).

\section{CONCLUSIONS}

This review gives evidence that ApoE genotype affects presymptomatic risk, diagnosis, prognosis, and treatment response for a variety of diseases. Despite these multiple associations, its inclusion in personalized medicine faces a major challenge because for most if not all diseases, ApoE is a risk and not a causal factor, and the many inconsistent findings in the literature suggest that ApoE-associated diseases are the result of complex interactions. Inclusion of ApoE in personalized medicine might be most effective as part of a broader panel of information. Likewise, the decision to assess ApoE genotype may best be made on a case-by-case basis.

Understanding the source of ApoE-interactions might yield great potential for disease prevention. It could be particularly important in patients with a family history of type III dysbetalipoproteinemia because by preventing other dyslipidemic factors it may be possible to postpone or stop symptomatic expression of the disease. Increasing evidence also suggests that improving one's lifestyle might help delay onset of AD and CVD. In such cases, one could however argue that good lifestyle habits should be promoted irrespective of genotype, and that assessing ApoE status would therefore not be needed. Even if this is correct, knowing that actions can be taken to modify a genetic risk is valuable, particularly in diseases such $\mathrm{AD}$ where no treatment is currently available.

In regard to treatment, ApoE status would probably not change the initial treatment plan, but this genetic information might help to guide recommendations for alternative treatments in cases of limited drug efficacy or adverse side effects. For instance, while ApoE4 carriers appear to be less responsive to lipid lowering therapy, they are more sensitive to diet and physical activity. Therefore, genotype specific treatment plans could be introduced as part of clinical care when a person displays 
suboptimal response to common treatments. ApoE genotype information could also be used to inform treatment in specific circumstances. For example, if a medical team is considering the pros and the cons of performing surgery in a frail older adult, knowing the patient's ApoE status could inform the decision. An ApoE4 carrier might be advised against the surgery. One area where ApoE should certainly be included is in clinical trials, particularly those concerning CVD and AD, as ApoE status clearly affects outcome. Following from this, ApoE could be used a target for new drug interventions given its broad range of action.

Ethical implications of ApoE genotyping should also be considered. For instance, what are the implications of disclosing that a person is an ApoE4/4 carrier? On one hand, the patient might be motivated to modify environmental factors that are within their control in order to reduce risk of associated diseases. On the other hand, the stress and potential adverse consequences caused by this information might be more detrimental than beneficial. There is not a large evidence base examining the psychological effects of disclosure, however in individuals with a familial history of $\mathrm{AD}$, disclosure of their ApoE genotype did not increase distress for e4carriers and indeed reduced it for non-e4 carriers (Green et al., 2009). It is also important to address whether genetic information would be available to health insurance companies, as this could profoundly affect access to care. Finally, one major concern raised about testing for ApoE genotype is that patients would be over-diagnosed and over-treated.

In conclusion, the effect of ApoE on disease risk is complex, however knowing the ApoE status of a person along with medical and family history, medication, and lifestyle could give valuable information for personalized medicine. More research into understanding the factors and mechanisms involved in ApoE-related interactions could improve awareness of disease susceptibility, prevention strategies, and guide person-centered therapeutic approaches.

\section{REFERENCES}

Adamis, D., Treloar, A., Martin, F. C., Gregson, N., Hamilton, G., and Macdonald, A. J. (2007). APOE and cytokines as biological markers for recovery of prevalent delirium in elderly medical inpatients. Int. J. Geriatr. Psychiatry 22, 688-694. doi: 10.1002 /gps.1732

Ahles, T. A., Saykin, A. J., Noll, W. W., Furstenberg, C. T., Guerin, S., Cole, B., et al. (2003). The relationship of APOE genotype to neuropsychological performance in long-term cancer survivors treated with standard dose chemotherapy. Psychooncology 12, 612-619. doi: 10.1002/pon.742

Andrade, S. E., Walker, A. M., Gottlieb, L. K., Hollenberg, N. K., Testa, M. A., Saperia, G. M., et al. (1995). Discontinuation of antihyperlipidemic drugs-do rates reported in clinical trials reflect rates in primary care settings? N. Engl. J. Med. 332, 1125-1131. doi: 10.1056/NEJM199504273321703

Andres, M. A., Feger, U., Nath, A., Munsaka, S., Jiang, C. S., and Chang, L. (2011). APOE epsilon 4 allele and CSF APOE on cognition in HIV-infected subjects. J. Neuroimmune Pharmacol. 6, 389-398. doi: 10.1007/s11481-010-9254-3

Ballantyne, C. M., Herd, J. A., Stein, E. A., Ferlic, L. L., Dunn, J. K., Gotto, A. M., et al. (2000). Apolipoprotein E genotypes and response of plasma lipids and progression-regression of coronary atherosclerosis to lipid-lowering drug therapy. J. Am. Coll. Cardiol. 36, 1572-1578. doi: 10.1016/S0735-1097(00) 00918-9

Ballard, C. G., Morris, C. M., Rao, H., O’Brien, J. T., Barber, R., Stephens, S., et al. (2004). APOE epsilon4 and cognitive decline in older stroke patients with early cognitive impairment. Neurology 63, 1399-1402. doi: 10.1212/01.WNL.0000141851.93193.17
Bedlack, R. S., Edelman, D., Gibbs, J. W. 3rd, Kelling, D., Strittmatter, W., Saunders, A. M., et al. (2003). APOE genotype is a risk factor for neuropathy severity in diabetic patients. Neurology 60, 1022-1024. doi: 10.1212/01.WNL.0000056689.50682.94

Bedlack, R. S., Strittmatter, W. J., and Morgenlander, J. C. (2000). Apolipoprotein E and neuromuscular disease: a critical review of the literature. Arch. Neurol. 57, 1561-1565. doi: 10.1001/archneur.57.11.1561

Bell, R. D., Winkler, E. A., Singh, I., Sagare, A. P., Deane, R., Wu, Z., et al. (2012). Apolipoprotein E controls cerebrovascular integrity via cyclophilin A. Nature 485, 512-516. doi: 10.1038/nature11087

Bell, R. D., and Zlokovic, B. V. (2009). Neurovascular mechanisms and blood-brain barrier disorder in Alzheimer's disease. Acta Neuropathol. 118, 103-113. doi: 10.1007/s00401-009-0522-3

Bennet, A. M., Di Angelantonio, E., Ye, Z., Wensley, F., Dahlin, A., Ahlbom, A., et al. (2007). Association of apolipoprotein E genotypes with lipid levels and coronary risk. JAMA 298, 1300-1311. doi: 10.1001/jama.298.11.1300

Bernstein, M. S., Costanza, M. C., James, R. W., Morris, M. A., Cambien, F., Raoux, S., et al. (2002). Physical activity may modulate effects of ApoE genotype on lipid profile. Arterioscler. Thromb. Vasc. Biol. 22, 133-140. doi: 10.1161/hq0102.101819

Bertram, L., and Tanzi, R. E. (2008). Thirty years of Alzheimer's disease genetics: the implications of systematic meta-analyses. Nat. Rev. Neurosci. 9, 768-778. doi: $10.1038 / \mathrm{nrn} 2494$

Bizzarro, A., Marra, C., Acciarri, A., Valenza, A., Tiziano, F. D., Brahe, C., et al. (2005). Apolipoprotein E epsilon4 allele differentiates the clinical response to donepezil in Alzheimer's disease. Dement. Geriatr. Cogn. Disord. 20, 254-261. doi: $10.1159 / 000087371$

Blazer, D. G., Burchett, B. B., and Fillenbaum, G. G. (2002). APOE epsilon4 and low cholesterol as risks for depression in a biracial elderly community sample. Am. J. Geriatr. Psychiatry 10, 515-520. doi: 10.1176/appi.ajgp.10.5.515

Brisson, D., Ledoux, K., Bosse, Y., St-Pierre, J., Julien, P., Perron, P., et al. (2002). Effect of apolipoprotein E, peroxisome proliferator-activated receptor alpha and lipoprotein lipase gene mutations on the ability of fenofibrate to improve lipid profiles and reach clinical guideline targets among hypertriglyceridemic patients. Pharmacogenetics 12, 313-320. doi: 10.1097/00008571-20020600000007

Bu, G. (2009). Apolipoprotein E and its receptors in Alzheimer's disease: pathways, pathogenesis and therapy. Nat. Rev. Neurosci. 10, 333-344. doi: $10.1038 / \mathrm{nrn} 2620$

Carmena, R., Roederer, G., Mailloux, H., Lussier-Cacan, S., and Davignon, J. (1993). The response to lovastatin treatment in patients with heterozygous familial hypercholesterolemia is modulated by apolipoprotein E polymorphism. Metab. Clin. Exp. 42, 895-901. doi: 10.1016/0026-0495(93)90066-W

Carmona, O., Masuet, C., Alia, P., Moral, E., Alonso-Magdalena, L., Casado, V., et al. (2011). Apolipoprotein alleles and the response to interferon-beta-1b in multiple sclerosis. Eur. Neurol. 65, 132-137. doi: 10.1159/000323982

Carriere, I., Fourrier-Reglat, A., Dartigues, J. F., Rouaud, O., Pasquier, F., Ritchie, K., et al. (2009). Drugs with anticholinergic properties, cognitive decline, and dementia in an elderly general population: the 3-city study. Arch. Intern. Med. 169, 1317-1324. doi: 10.1001/archinternmed.2009.229

Chamelian, L., Reis, M., and Feinstein, A. (2004). Six-month recovery from mild to moderate traumatic brain injury: the role of APOE-epsilon4 allele. Brain 127, 2621-2628. doi: 10.1093/brain/awh296

Champagne, D., Pearson, D., Dea, D., Rochford, J., and Poirier, J. (2003). The cholesterol-lowering drug probucol increases apolipoprotein E production in the hippocampus of aged rats: implications for Alzheimer's disease. Neuroscience 121, 99-110. doi: 10.1016/S0306-4522(03)00361-0

Choi, S. H., Kim, S. Y., Na, H. R., Kim, B. K., Yang, D. W., Kwon, J. C., et al. (2008). Effect of ApoE genotype on response to donepezil in patients with Alzheimer's disease. Dement. Geriatr. Cogn. Disord. 25, 445-450. doi: 10.1159/000124752

Corder, E. H., Robertson, K., Lannfelt, L., Bogdanovic, N., Eggertsen, G., Wilkins, J., et al. (1998). HIV-infected subjects with the E4 allele for APOE have excess dementia and peripheral neuropathy. Nat. Med. 4, 1182-1184. doi: $10.1038 / 2677$

Corder, E. H., Saunders, A. M., Risch, N. J., Strittmatter, W. J., Schmechel, D. E., Gaskell, P. C., et al. (1994). Protective effect of apolipoprotein E type 2 allele for late onset Alzheimer disease. Nat. Genet. 7, 180-184.

Corder, E. H., Saunders, A. M., Strittmatter, W. J., Schmechel, D. E., Gaskell, P. C., Small, G. W., et al. (1993). Gene dose of apolipoprotein E type 4 allele and 
the risk of Alzheimer's disease in late onset families. Science 261, 921-923. doi: 10.1126/science. 8346443

Corella, D., Guillen, M., Saiz, C., Portoles, O., Sabater, A., Cortina, S., et al. (2001). Environmental factors modulate the effect of the APOE genetic polymorphism on plasma lipid concentrations: ecogenetic studies in a mediterranean Spanish population. Metabolism 50, 936-944. doi: 10.1053/meta.2001.24867

Craft, S., Teri, L., Edland, S. D., Kukull, W. A., Schellenberg, G., McCormick, W. C., et al. (1998). Accelerated decline in apolipoprotein E-epsilon4 homozygotes with Alzheimer's disease. Neurology 51, 149-153. doi: 10.1212/WNL.51.1.149

Crawford, F., Wood, M., Ferguson, S., Mathura, V., Gupta, P., Humphrey, J., et al. (2009). Apolipoprotein E-genotype dependent hippocampal and cortical responses to traumatic brain injury. Neuroscience 159, 1349-1362. doi: 10.1016/j.neuroscience.2009.01.033

De Andrade, F. M., Bulhoes, A. C., Maluf, S. W., Schuch, J. B., Voigt, F., Lucatelli, J. F., et al. (2010). The influence of nutrigenetics on the lipid profile: interaction between genes and dietary habits. Biochem. Genet. 48, 342-355. doi: 10.1007/s10528-010-9331-6

Deane, R., Sagare, A., Hamm, K., Parisi, M., Lane, S., Finn, M. B., et al. (2008). apoE isoform-specific disruption of amyloid beta peptide clearance from mouse brain. J. Clin. Invest. 118, 4002-4013. doi: 10.1172/JCI36663

De Bont, N., Netea, M. G., Demacker, P. N., Verschueren, I., Kullberg, B. J., Van Dijk, K. W., et al. (1999). Apolipoprotein E knock-out mice are highly susceptible to endotoxemia and Klebsiella pneumoniae infection. J. Lipid Res. 40, 680-685. doi: 10.1016/S0021-9150(99)80362-1

De La Fuente-Fernandez, R., Nunez, M. A., and Lopez, E. (1999). The apolipoprotein $\mathrm{E}$ epsilon 4 allele increases the risk of drug-induced hallucinations in Parkinson's disease. Clin. Neuropharmacol. 22, 226-230.

Dergunov, A. D. (2011). Apolipoprotein E genotype as a most significant predictor of lipid response at lipid-lowering therapy: mechanistic and clinical studies. Biomed. Pharmacother. 65, 597-603. doi: 10.1016/j.biopha.2011.04.003

Djousse, L., Myers, R. H., Province, M. A., Hunt, S. C., Eckfeldt, J. H., Evans, G., et al. (2002). Influence of apolipoprotein E, smoking, and alcohol intake on carotid atherosclerosis: national heart, lung, and blood institute family heart study. Stroke 33, 1357-1361. doi: 10.1161/01.STR.0000014325.54063.1A

Dong, L. M., and Weisgraber, K. H. (1996). Human apolipoprotein E4 domain interaction. Arginine 61 and glutamic acid 255 interact to direct the preference for very low density lipoproteins. J. Biol. Chem. 271, 19053-19057.

Dong, L. M., Wilson, C., Wardell, M. R., Simmons, T., Mahley, R. W., Weisgraber, K. H., et al. (1994). Human apolipoprotein E. Role of arginine 61 in mediating the lipoprotein preferences of the E3 and E4 isoforms. J. Biol. Chem. 269, 22358-22365.

Drzezga, A., Grimmer, T., Henriksen, G., Muhlau, M., Perneczky, R., Miederer, I., et al. (2009). Effect of APOE genotype on amyloid plaque load and gray matter volume in Alzheimer disease. Neurology 72, 1487-1494. doi: 10.1212/WNL.0b013e3181a2e8d0

Eichner, J. E., Dunn, S. T., Perveen, G., Thompson, D. M., Stewart, K. E., and Stroehla, B. C. (2002). Apolipoprotein E polymorphism and cardiovascular disease: a HuGE review. Am. J. Epidemiol. 155, 487-495. doi: 10.1093/aje/155.6.487

Elosua, R., Demissie, S., Cupples, L. A., Meigs, J. B., Wilson, P. W., Schaefer, E. J., et al. (2003). Obesity modulates the association among APOE genotype, insulin, and glucose in men. Obes. Res. 11, 1502-1508. doi: 10.1038/oby.2003.201

Evans, S., Gray, M. A., Dowell, N. G., Tabet, N., Tofts, P. S., King, S. L., et al. (2013). APOE E4 Carriers show prospective memory enhancement under nicotine, and evidence for specialisation within medial BA10. Neuropsychopharmacology 38 , 655-663. doi: 10.1038/npp.2012.230

Farlow, M. R., Lahiri, D. K., Poirier, J., Davignon, J., and Hui, S. (1996). Apolipoprotein E genotype and gender influence response to tacrine therapy. Ann. N.Y. Acad. Sci. 802, 101-110. doi: 10.1111/j.1749-6632.1996.tb 32603.x

Farlow, M. R., Lahiri, D. K., Poirier, J., Davignon, J., Schneider, L., and Hui, S. L. (1998). Treatment outcome of tacrine therapy depends on apolipoprotein genotype and gender of the subjects with Alzheimer's disease. Neurology 50, 669-677. doi: 10.1212/WNL.50.3.669

Ferrari, C., Xu, W. L., Wang, H. X., Winblad, B., Sorbi, S., Qiu, C., et al. (2013). How can elderly apolipoprotein E epsilon4 carriers remain free from dementia? Neurobiol. Aging 34, 13-21. doi: 10.1016/j.neurobiolaging.2012.03.003

Gauthier, S., Reisberg, B., Zaudig, M., Petersen, R. C., Ritchie, K., Broich, K., et al. (2006). Mild cognitive impairment. Lancet 367, 1262-1270. doi: 10.1016/S01406736(06)68542-5
Grainger, D. J., Reckless, J., and McKilligin, E. (2004). Apolipoprotein E modulates clearance of apoptotic bodies in vitro and in vivo, resulting in a systemic proinflammatory state in apolipoprotein E-deficient mice. J. Immunol. 173, 6366-6375. doi: 10.4049/jimmunol.173.10.6366

Green, R. C., Roberts, J. S., Cupples, L. A., Relkin, N. R., Whitehouse, P. J., Brown, T., et al. (2009). Disclosure of APOE genotype for risk of Alzheimer's disease. $N$. Engl. J. Med. 361, 245-254. doi: 10.1056/NEJMoa0809578

Grehan, S., Tse, E., and Taylor, J. M. (2001). Two distal downstream enhancers direct expression of the human apolipoprotein $\mathrm{E}$ gene to astrocytes in the brain. J. Neurosci. 21, 812-822.

Growdon, J. H., Locascio, J. J., Corkin, S., Gomez-Isla, T., and Hyman, B. T. (1996). Apolipoprotein E genotype does not influence rates of cognitive decline in Alzheimer's disease. Neurology 47, 444-448. doi: 10.1212/WNL.47.2.444

Gueguen, R., Visvikis, S., Steinmetz, J., Siest, G., and Boerwinkle, E. (1989). An analysis of genotype effects and their interactions by using the apolipoprotein $\mathrm{E}$ polymorphism and longitudinal data. Am. J. Hum. Genet. 45, 793-802.

Guerrero, A. L., Tejero, M. A., Gutierrez, F., Martin-Polo, J., Iglesias, F., Laherran, E., et al. (2011). Influence of APOE gene polymorphisms on interferonbeta treatment response in multiple sclerosis. Neurologia 26, 137-142. doi: 10.1016/j.nrl.2010.06.003

Guo, L., Ladu, M. J., and Van Eldik, L. J. (2004). A dual role for apolipoprotein e in neuroinflammation: anti- and pro-inflammatory activity. J. Mol. Neurosci. 23, 205-212. doi: 10.1385/JMN:23:3:205

Guo, Z. D., Sun, X. C., and Zhang, J. H. (2011). The role of apolipoprotein e in the pathological events following subarachnoid hemorrhage: a review. Acta Neurochir. Suppl. 110, 5-7. doi: 10.1007/978-3-7091-0356-2_1

Hatters, D. M., Peters-Libeu, C. A., and Weisgraber, K. H. (2006). Apolipoprotein E structure: insights into function. Trends Biochem. Sci. 31, 445-454. doi: 10.1016/j.tibs.2006.06.008

Hiekkanen, H., Kurki, T., Brandstack, N., Kairisto, V., and Tenovuo, O. (2009). Association of injury severity, MRI-results and ApoE genotype with 1-year outcome in mainly mild TBI: a preliminary study. Brain Inj. 23, 396-402. doi: $10.1080 / 02699050902926259$

Huang, X., Chen, P. C., and Poole, C. (2004). APOE-[epsilon]2 allele associated with higher prevalence of sporadic Parkinson disease. Neurology 62, 2198-2202. doi: 10.1212/01.WNL.0000130159.28215.6A

Irie, F., Masaki, K. H., Petrovitch, H., Abbott, R. D., Ross, G. W., Taaffe, D. R., et al. (2008). Apolipoprotein E epsilon4 allele genotype and the effect of depressive symptoms on the risk of dementia in men: the Honolulu-Asia aging study. Arch. Gen. Psychiatry 65, 906-912. doi: 10.1001/archpsyc.65.8.906

Jiang, Q., Lee, C. Y., Mandrekar, S., Wilkinson, B., Cramer, P., Zelcer, N., et al. (2008). ApoE promotes the proteolytic degradation of Abeta. Neuron 58, 681-693. doi: 10.1016/j.neuron.2008.04.010

Khan, T. A., Shah, T., Prieto, D., Zhang, W., Price, J., Fowkes, G. R., et al. (2013). Apolipoprotein E genotype, cardiovascular biomarkers and risk of stroke: systematic review and meta-analysis of 14,015 stroke cases and pooled analysis of primary biomarker data from up to 60,883 individuals. Int. J. Epidemiol. 42, 475-492. doi: 10.1093/ije/dyt034

Kim, J., Basak, J. M., and Holtzman, D. M. (2009). The role of apolipoprotein E in Alzheimer's disease. Neuron 63, 287-303. doi: 10.1016/j.neuron.2009.06.026

Kim, J. M., Kim, S. Y., Bae, K. Y., Kim, S. W., Shin, I. S., Yang, S. J., et al. (2010). Apolipoprotein e4 genotype and depressive symptoms as risk factors for dementia in an older korean population. Psychiatry Investig. 7, 135-140. doi: 10.4306/pi.2010.7.2.135

Kim, J. M., Stewart, R., Kim, S. Y., Kim, S. W., Bae, K. Y., Yang, S. J., et al. (2011). Synergistic associations of depression and apolipoprotein E genotype with incidence of dementia. Int. J. Geriatr. Psychiatry 26, 893-898. doi: 10.1002/gps.2621

Kleiman, T., Zdanys, K., Black, B., Rightmer, T., Grey, M., Garman, K., et al. (2006). Apolipoprotein E epsilon4 allele is unrelated to cognitive or functional decline in Alzheimer's disease: retrospective and prospective analysis. Dement. Geriatr. Cogn. Disord. 22, 73-82. doi: 10.1159/000093316

Kokkinos, P. F., and Fernhall, B. (1999). Physical activity and high density lipoprotein cholesterol levels: what is the relationship? Sports Med. 28, 307-314.

Kuhlmann, I., Minihane, A. M., Huebbe, P., Nebel, A., and Rimbach, G. (2010). Apolipoprotein E genotype and hepatitis C, HIV and herpes simplex disease risk: a literature review. Lipids Health Dis. 9:8. doi: 10.1186/1476511X-9-8

Kulminski, A. M., Culminskaya, I., Ukraintseva, S. V., Arbeev, K. G., Arbeeva, L., Wu, D., et al. (2011). Trade-off in the effects of the apolipoprotein E 
polymorphism on the ages at onset of CVD and cancer influences human lifespan. Aging Cell 10, 533-541. doi: 10.1111/j.1474-9726.2011.00689.x

Ladu, M. J., Falduto, M. T., Manelli, A. M., Reardon, C. A., Getz, G. S., and Frail, D. E. (1994). Isoform-specific binding of apolipoprotein E to beta-amyloid. J. Biol. Chem. 269, 23403-23406.

Lahoz, C., Schaefer, E. J., Cupples, L. A., Wilson, P. W., Levy, D., Osgood, D., et al. (2001). Apolipoprotein E genotype and cardiovascular disease in the framingham heart study. Atherosclerosis 154, 529-537. doi: 10.1016/S00219150(00)00570-0

Leduc, V., Domenger, D., De Beaumont, L., Lalonde, D., Belanger-Jasmin, S., and Poirier, J. (2011). Function and comorbidities of apolipoprotein e in Alzheimer's disease. Int. J. Alzheimers Dis. 2011:974361. doi: 10.4061/2011/974361

Leung, J. M., Sands, L. P., Wang, Y., Poon, A., Kwok, P. Y., Kane, J. P., et al. (2007). Apolipoprotein E e4 allele increases the risk of early postoperative delirium in older patients undergoing noncardiac surgery. Anesthesiology 107, 406-411. doi: 10.1097/01.anes.0000278905.07899.df

Lichtman, S. W., Seliger, G., Tycko, B., and Marder, K. (2000). Apolipoprotein E and functional recovery from brain injury following postacute rehabilitation. Neurology 55, 1536-1539. doi: 10.1212/WNL.55.10.1536

Liu, C. C., Kanekiyo, T., Xu, H., and Bu, G. (2013). Apolipoprotein E and Alzheimer disease: risk, mechanisms and therapy. Nat. Rev. Neurol. 9, 106-118. doi: 10.1038/nrneurol.2012.263

Mahley, R. W. (1988). Apolipoprotein E: cholesterol transport protein with expanding role in cell biology. Science 240, 622-630. doi: 10.1126/science.3283935

Mahley, R. W., and Huang, Y. (2009). Alzheimer disease: multiple causes, multiple effects of apolipoprotein E4, and multiple therapeutic approaches. Ann. Neurol. 65, 623-625. doi: 10.1002/ana.21736

Mahley, R. W., and Huang, Y. (2012a). Apolipoprotein e sets the stage: response to injury triggers neuropathology. Neuron 76, 871-885. doi: 10.1016/j.neuron.2012.11.020

Mahley, R. W., and Huang, Y. (2012b). Small-molecule structure correctors target abnormal protein structure and function: structure corrector rescue of apolipoprotein E4-associated neuropathology. J. Med. Chem. 55, 8997-9008. doi: $10.1021 /$ jm 3008618

Mahley, R. W., Huang, Y., and Rall, S. C. Jr. (1999). Pathogenesis of type III hyperlipoproteinemia (dysbetalipoproteinemia). questions, quandaries, and paradoxes. J. Lipid Res. 40, 1933-1949.

Mahley, R. W., Weisgraber, K. H., and Huang, Y. (2009). Apolipoprotein E: structure determines function, from atherosclerosis to Alzheimer's disease to AIDS. J. Lipid Res. 50(Suppl.), S183-S188. doi: 10.1194/jlr.R800069-JLR200

Maitland-Van Der Zee, A. H., Stricker, B. H., Klungel, O. H., Mantel-Teeuwisse, A. K., Kastelein, J. J., Hofman, A., et al. (2003). Adherence to and dosing of betahydroxy-beta-methylglutaryl coenzyme a reductase inhibitors in the general population differs according to apolipoprotein E-genotypes. Pharmacogenetics 13, 219-223. doi: 10.1097/00008571-200304000-00006

Marchant, N. L., King, S. L., Tabet, N., and Rusted, J. M. (2010). Positive effects of cholinergic stimulation favor young APOE epsilon4 carriers. Neuropsychopharmacology 35, 1090-1096. doi: 10.1038/npp.2009.214

Marques-Vidal, P., Bongard, V., Ruidavets, J. B., Fauvel, J., Hanaire-Broutin, H., Perret, B., et al. (2003). Obesity and alcohol modulate the effect of apolipoprotein E polymorphism on lipids and insulin. Obes. Res. 11, 1200-1206. doi: 10.1038/oby.2003.165

Marrugat, J., Elosua, R., Covas, M. I., Molina, L., and Rubies-Prat, J. (1996). Amount and intensity of physical activity, physical fitness, and serum lipids in men. The MARATHOM Investigators. Am. J. Epidemiol. 143, 562-569. doi: 10.1093/oxfordjournals.aje.a008786

Martinez-Gonzalez, N. A., and Sudlow, C. L. (2006). Effects of apolipoprotein E genotype on outcome after ischaemic stroke, intracerebral haemorrhage and subarachnoid haemorrhage. J. Neurol. Neurosurg. Psychiatr. 77, 1329-1335. doi: 10.1136/jnnp.2006.097543

Martins, C. A., Oulhaj, A., De Jager, C. A., and Williams, J. H. (2005). APOE alleles predict the rate of cognitive decline in Alzheimer disease: a nonlinear model. Neurology 65, 1888-1893. doi: 10.1212/01.wnl.0000188871.74093.12

Masson, L. F., McNeill, G., and Avenell, A. (2003). Genetic variation and the lipid response to dietary intervention: a systematic review. Am. J. Clin. Nutr. 77, 1098-1111.

Mauch, D. H., Nagler, K., Schumacher, S., Goritz, C., Muller, E. C., Otto, A., et al. (2001). CNS synaptogenesis promoted by glia-derived cholesterol. Science 294, 1354-1357. doi: 10.1126/science.294.5545.1354
Mauricio, M., O’Hara, R., Yesavage, J. A., Friedman, L., Kraemer, H. C., Van De Water, M., et al. (2000). A longitudinal study of apolipoprotein-E genotype and depressive symptoms in community-dwelling older adults. Am. J. Geriatr. Psychiatry 8, 196-200. doi: 10.1097/00019442-200008000-00003

Meng, X., and D'Arcy, C. (2013). Apolipoprotein E gene, environmental risk factors, and their interactions in dementia among seniors. Int. J. Geriatr. Psychiatry 28, 1005-1014. doi: 10.1002/gps.3918

Morris, J. C., Roe, C. M., Xiong, C., Fagan, A. M., Goate, A. M., Holtzman, D. M., et al. (2010). APOE predicts amyloid-beta but not tau Alzheimer pathology in cognitively normal aging. Ann. Neurol. 67, 122-131. doi: 10.1002/ana.21843

Mosconi, L., Perani, D., Sorbi, S., Herholz, K., Nacmias, B., Holthoff, V., et al. (2004). MCI conversion to dementia and the APOE genotype: a prediction study with FDG-PET. Neurology 63, 2332-2340. doi: 10.1212/01.WNL.0000147469.18313.3B

Nestel, P., Simons, L., Barter, P., Clifton, P., Colquhoun, D., Hamilton-Craig, I., et al. (1997). A comparative study of the efficacy of simvastatin and gemfibrozil in combined hyperlipoproteinemia: prediction of response by baseline lipids, apo E genotype, lipoprotein(a) and insulin. Atherosclerosis 129, 231-239. doi: 10.1016/S0021-9150(96)06031-5

Nieminen, T., Kahonen, M., Viiri, L. E., Gronroos, P., and Lehtimaki, T. (2008). Pharmacogenetics of apolipoprotein E gene during lipid-lowering therapy: lipid levels and prevention of coronary heart disease. Pharmacogenomics 9, 1475-1486. doi: 10.2217/14622416.9.10.1475

Niti, M., Yap, K. B., Kua, E. H., Tan, C. H., and Ng, T. P. (2008). Physical, social and productive leisure activities, cognitive decline and interaction with APOEepsilon 4 genotype in Chinese older adults. Int. Psychogeriatr. 20, 237-251. doi: $10.1017 /$ S1041610207006655

Offit, K. (2011). Personalized medicine: new genomics, old lessons. Hum. Genet. 130, 3-14. doi: 10.1007/s00439-011-1028-3

O'Malley, J. P., and Illingworth, D. R. (1990). The influence of apolipoprotein E phenotype on the response to lovastatin therapy in patients with heterozygous familial hypercholesterolemia. Metabolism 39, 150-154. doi: 10.1016/00260495(90)90068-N

Ordovas, J. M., Lopez-Miranda, J., Perez-Jimenez, F., Rodriguez, C., Park, J. S., Cole, T., et al. (1995). Effect of apolipoprotein E and A-IV phenotypes on the low density lipoprotein response to HMG CoA reductase inhibitor therapy. Atherosclerosis 113, 157-166. doi: 10.1016/0021-9150(94)05439-P

Panza, F., Frisardi, V., Seripa, D., D’Onofrio, G., Santamato, A., Masullo, C., et al. (2012). Apolipoprotein E genotypes and neuropsychiatric symptoms and syndromes in late-onset Alzheimer's disease. Ageing Res. Rev. 11, 87-103. doi: 10.1016/j.arr.2011.06.005

Pedro-Botet, J., Schaefer, E. J., Bakker-Arkema, R. G., Black, D. M., Stein, E. M., Corella, D., et al. (2001). Apolipoprotein E genotype affects plasma lipid response to atorvastatin in a gender specific manner. Atherosclerosis 158, 183-193. doi: 10.1016/S0021-9150(01)00410-5

Petersen, R. C., Thomas, R. G., Grundman, M., Bennett, D., Doody, R., Ferris, S., et al. (2005). Vitamin E and donepezil for the treatment of mild cognitive impairment. N. Engl. J. Med. 352, 2379-2388. doi: 10.1056/NEJMoa 050151

Pitas, R. E., Boyles, J. K., Lee, S. H., Hui, D., and Weisgraber, K. H. (1987). Lipoproteins and their receptors in the central nervous system. Characterization of the lipoproteins in cerebrospinal fluid and identification of apolipoprotein B,E(LDL) receptors in the brain. J. Biol. Chem. 262, 14352-14360.

Poirier, J., Davignon, J., Bouthillier, D., Kogan, S., Bertrand, P., and Gauthier, S. (1993). Apolipoprotein E polymorphism and Alzheimer's disease. Lancet 342, 697-699. doi: 10.1016/0140-6736(93)91705-Q

Poirier, J., Delisle, M. C., Quirion, R., Aubert, I., Farlow, M., Lahiri, D., et al. (1995). Apolipoprotein E4 allele as a predictor of cholinergic deficits and treatment outcome in Alzheimer disease. Proc. Natl. Acad. Sci. U.S.A. 92, 12260-12264. doi: 10.1073/pnas.92.26.12260

Ponsford, J., McLaren, A., Schonberger, M., Burke, R., Rudzki, D., Olver, J., et al. (2011). The association between apolipoprotein $\mathrm{E}$ and traumatic brain injury severity and functional outcome in a rehabilitation sample. J. Neurotrauma 28 , 1683-1692. doi: 10.1089/neu.2010.1623

Porrata-Doria, T., Matta, J. L., and Acevedo, S. F. (2010). Apolipoprotein E allelic frequency altered in women with early-onset breast cancer. Breast Cancer (Auckl). 4, 43-48.

Ramaswamy, S., and Kordower, J. H. (2011). Gene therapy for Huntington's disease. Neurobiol. Dis. 48, 243-254. doi: 10.1016/j.nbd.2011.12.030 
Rannikmae, K., Samarasekera, N., Martinez-Gonzalez, N. A., Al-Shahi Salman, R., and Sudlow, C. L. (2013). Genetics of cerebral amyloid angiopathy: systematic review and meta-analysis. J. Neurol. Neurosurg. Psychiatry 84, 901-908. doi: 10.1136/jnnp-2012-303898

Reed, B., Villeneuve, S., Mack, W., Decarli, C., Chui, H. C., and Jagust, W. (2014). Associations between serum cholesterol levels and cerebral amyloidosis. JAMA Neurol. 71, 195-200. doi: 10.1001/jamaneurol.2013.5390

Risner, M. E., Saunders, A. M., Altman, J. F., Ormandy, G. C., Craft, S., Foley, I. M., et al. (2006). Efficacy of rosiglitazone in a genetically defined population with mild-to-moderate Alzheimer's disease. Pharmacogenomics J. 6, 246-254. doi: 10.1038/sj.tpj.6500369

Roselaar, S. E., and Daugherty, A. (1998). Apolipoprotein E-deficient mice have impaired innate immune responses to Listeria monocytogenes in vivo. J. Lipid Res. 39, 1740-1743.

Rubino, E., Vacca, A., Govone, F., De Martino, P., Pinessi, L., and Rainero, I. (2013). Apolipoprotein E polymorphisms in frontotemporal lobar degeneration: a meta-analysis. Alzheimers Dement. 9, 706-713. doi: 10.1016/j.jalz.2012. 10.013

Saadat, M. (2012). Apolipoprotein E (APOE) polymorphisms and susceptibility to breast cancer: a meta-analysis. Cancer Res. Treat. 44, 121-126. doi: 10.4143/crt.2012.44.2.121

Saito, M., Eto, M., Nitta, H., Kanda, Y., Shigeto, M., Nakayama, K., et al. (2004). Effect of apolipoprotein E4 allele on plasma LDL cholesterol response to diet therapy in type 2 diabetic patients. Diabetes Care 27, 1276-1280. doi: 10.2337/diacare.27.6.1276

Salloway, S., Sperling, R., Fox, N. C., Blennow, K., Klunk, W., Raskind, M., et al. (2014). Two phase 3 trials of bapineuzumab in mild-to-moderate Alzheimer's disease. N. Engl. J. Med. 370, 322-333. doi: 10.1056/NEJMoa 1304839

Sanllehy, C., Casals, E., Rodriguez-Villar, C., Zambon, D., Ojuel, J., Ballesta, A. M., et al. (1998). Lack of interaction of apolipoprotein E phenotype with the lipoprotein response to lovastatin or gemfibrozil in patients with primary hypercholesterolemia. Metab. Clin. Exp. 47, 560-565. doi: 10.1016/S00260495(98)90240-2

Schmidt, C., Becker, H., and Zerr, I. (2014). Cerebrospinal fluid apolipoprotein e concentration and severity of cognitive impairment in patients with newly diagnosed Alzheimer's disease. Am. J. Alzheimers Dis. Other Demen. 29, 54-60. doi: 10.1177/1533317513505133

Schmidt, C., Wolff, M., Von Ahsen, N., and Zerr, I. (2012). Alzheimer's disease: genetic polymorphisms and rate of decline. Dement. Geriatr. Cogn. Disord. 33, 84-89. doi: 10.1159/000336790

Shore, V. G., and Shore, B. (1973). Heterogeneity of human plasma very low density lipoproteins. separation of species differing in protein components. Biochemistry 12, 502-507.

Smith, J. C., Nielson, K. A., Woodard, J. L., Seidenberg, M., Durgerian, S., Hazlett, K. E., et al. (2014). Physical activity reduces hippocampal atrophy in elders at genetic risk for Alzheimer's disease. Front. Aging Neurosci. 6:61. doi: 10.3389/fnagi.2014.00061

Song, F., Poljak, A., Crawford, J., Kochan, N. A., Wen, W., Cameron, B., et al. (2012). Plasma apolipoprotein levels are associated with cognitive status and decline in a community cohort of older individuals. PLOS ONE 7:e34078. doi: 10.1371/journal.pone.0034078

Song, Y., Stampfer, M. J., and Liu, S. (2004). Meta-analysis: apolipoprotein E genotypes and risk for coronary heart disease. Ann. Intern. Med. 141, 137-147. doi: 10.7326/0003-4819-141-2-200407200-00013

Stehle, S., Kirchheiner, J., Lazar, A., and Fuhr, U. (2008). Pharmacogenetics of oral anticoagulants: a basis for dose individualization. Clin. Pharmacokinet. 47, 565-594. doi: 10.2165/00003088-200847090-00002

Stern, Y., Brandt, J., Albert, M., Jacobs, D. M., Liu, X., Bell, K., et al. (1997). The absence of an apolipoprotein epsilon4 allele is associated with a more aggressive form of Alzheimer's disease. Ann. Neurol. 41, 615-620. doi: 10.1002/ana.410410510

Strittmatter, W. J., Saunders, A. M., Schmechel, D., Pericak-Vance, M., Enghild, J., Salvesen, G. S., et al. (1993). Apolipoprotein E: high-avidity binding to betaamyloid and increased frequency of type 4 allele in late-onset familial Alzheimer disease. Proc. Natl. Acad. Sci. U.S.A. 90, 1977-1981. doi: 10.1073/pnas.90. 5.1977

Tokuda, T., Calero, M., Matsubara, E., Vidal, R., Kumar, A., Permanne, B., et al. (2000). Lipidation of apolipoprotein $\mathrm{E}$ influences its isoform-specific interaction with Alzheimer's amyloid beta peptides. Biochem. J. 348(pt 2), 359-365. doi: 10.1042/0264-6021:3480359

Tsuzuki, S., Murano, T., Watanabe, H., Itoh, Y., Miyashita, Y., and Shirai, K. (1998). [The examination of apoE phenotypes in diabetic patients with peripheral neuropathy]. Rinsho Byori 46, 829-833.

Verghese, P. B., Castellano, J. M., and Holtzman, D. M. (2011). Apolipoprotein $\mathrm{E}$ in Alzheimer's disease and other neurological disorders. Lancet Neurol. 10, 241-252. doi: 10.1016/S1474-4422(10)70325-2

Villeneuve, S., and Belleville, S. (2012). The nature of memory failure in mild cognitive impairment: examining association with neurobiological markers and effect of progression. Neurobiol. Aging 33, 1967-1978. doi: 10.1016/j.neurobiolaging. 2011.10.004

Villeneuve, S., Massoud, F., Bocti, C., Gauthier, S., and Belleville, S. (2011a). The nature of episodic memory deficits in MCI with and without vascular burden. Neuropsychologia 49, 3027-3035. doi: 10.1016/j.neuropsychologia.2011.07.001

Villeneuve, S., Pepin, V., Rahayel, S., Bertrand, J. A., De Lorimier, M., Rizk, A., et al. (2012). Mild cognitive impairment in moderate to severe COPD: a preliminary study. Chest 142, 1516-1523. doi: 10.1378/chest.11-3035

Villeneuve, S., Reed, B., Madison, C., Wirth, M., Kriger, S., Marchant, N., et al. (2014). Vascular risk and $\mathrm{A} \beta$ interact to reduce cortical thickness in AD vulnerable brain regions. Neurology 83, 40-47. doi: 10.1212/WNL.00000000000 00550

Villeneuve, S., Rodrigues-Brazete, J., Joncas, S., Postuma, R. B., Latreille, V., and Gagnon, J. F. (2011b). Validity of the mattis dementia rating scale to detect mild cognitive impairment in Parkinson's disease and REM sleep behavior disorder. Dement. Geriatr. Cogn. Disord. 31, 210-217. doi: 10.1159/000326212

Vitek, M. P., Brown, C. M., and Colton, C. A. (2009). APOE genotype-specific differences in the innate immune response. Neurobiol. Aging 30, 1350-1360. doi: 10.1016/j.neurobiolaging.2007.11.014

Vos, S. J., Van Rossum, I. A., Verhey, F., Knol, D. L., Soininen, H., Wahlund, L. O., et al. (2013). Prediction of Alzheimer disease in subjects with amnestic and nonamnestic MCI. Neurology 80, 1124-1132. doi: 10.1212/WNL.0b013e318 $288690 \mathrm{c}$

Wei, Y., Tang, Y., He, W., Qu, Z., Zeng, J., and Qin, C. (2014). APOE gene polymorphisms and susceptibility to Creutzfeldt-Jakob disease. J. Clin. Neurosci. 21, 390-394. doi: 10.1016/j.jocn.2013.07.019

Weisgraber, K. H., Innerarity, T. L., and Mahley, R. W. (1982). Abnormal lipoprotein receptor-binding activity of the human $\mathrm{E}$ apoprotein due to cysteinearginine interchange at a single site. J. Biol. Chem. 257, 2518-2521.

Wirth, M., Villeneuve, S., Renaud La, J., Marks, S., and Jagust, W. (2014). Geneenvironment interactions: lifetime cognitive activity, APOE genotype, and betaamyloid burden. J. Neurosci. 34, 8612-8617. doi: 10.1523/JNEUROSCI.4612-13. 2014

Xue, P., Niu, W. Q., Jiang, Z. Y., Zheng, M. H., and Fei, J. (2012). A metaanalysis of apolipoprotein E gene epsilon2/epsilon3/epsilon4 polymorphism for gallbladder stone disease. PLoS ONE 7:e45849. doi: 10.1371/journal.pone. 0045849

Yang, D. S., Small, D. H., Seydel, U., Smith, J. D., Hallmayer, J., Gandy, S. E., et al. (1999). Apolipoprotein E promotes the binding and uptake of beta-amyloid into Chinese hamster ovary cells in an isoform-specific manner. Neuroscience 90, 1217-1226. doi: 10.1016/S0306-4522(98)00561-2

Ye, S., Huang, Y., Mullendorff, K., Dong, L., Giedt, G., Meng, E. C., et al. (2005). Apolipoprotein (apo) E4 enhances amyloid beta peptide production in cultured neuronal cells: apoE structure as a potential therapeutic target. Proc. Natl. Acad. Sci. U.S.A. 102, 18700-18705. doi: 10.1073/pnas.0508693102

Yin, Y. W., Qiao, L., Sun, Q. Q., Hu, A. M., Liu, H. L., Wang, Q., et al. (2013). Influence of apolipoprotein E gene polymorphism on development of type 2 diabetes mellitus in Chinese han population: a meta-analysis of 29 studies. Metabolism 63, 532-541. doi: 10.1016/j.metabol.2013.12.008

Yin, Y. W., Zhang, Y. D., Wang, J. Z., Li, B. H., Yang, Q. W., Fang, C. Q., et al. (2012). Association between apolipoprotein E gene polymorphism and the risk of multiple sclerosis: a meta-analysis of 6977 subjects. Gene 511, 12-17. doi: 10.1016/j.gene.2012.09.010

Zeng, Y., Hughes, C. L., Lewis, M. A., Li, J., and Zhang, F. (2011). Interactions between life stress factors and carrying the APOE4 allele adversely impact selfreported health in old adults. J. Gerontol. A Biol. Sci. Med. Sci. 66, 1054-1061. doi: 10.1093/gerona/glr106

Zhang, H., Wu, L. M., and Wu, J. (2011). Cross-talk between apolipoprotein E and cytokines. Mediators Inflamm. 2011:949072. doi: 10.1155/2011/949072 
Zlokovic, B. V. (2011). Neurovascular pathways to neurodegeneration in Alzheimer's disease and other disorders. Nat. Rev. Neurosci. 12, 723-738. doi: 10.1038/nrn3114

Zuccaro, P., Mombelli, G., Calabresi, L., Baldassarre, D., Palmi, I., and Sirtori, C. R. (2007). Tolerability of statins is not linked to CYP450 polymorphisms, but reduced CYP2D6 metabolism improves cholesteraemic response to simvastatin and fluvastatin. Pharmacol. Res. 55, 310-317. doi: 10.1016/j.phrs.2006.12.009

Conflict of Interest Statement: The authors declare that the research was conducted in the absence of any commercial or financial relationships that could be construed as a potential conflict of interest.
Received: 18 March 2014; accepted: 18 June 2014; published online: 08 July 2014. Citation: Villeneuve S, Brisson D, Marchant NL and Gaudet D (2014) The potential applications of Apolipoprotein E in personalized medicine. Front. Aging Neurosci. 6:154. doi: 10.3389/fnagi.2014.00154

This article was submitted to the journal Frontiers in Aging Neuroscience.

Copyright (c) 2014 Villeneuve, Brisson, Marchant and Gaudet. This is an openaccess article distributed under the terms of the Creative Commons Attribution License (CC BY). The use, distribution or reproduction in other forums is permitted, provided the original author(s) or licensor are credited and that the original publication in this journal is cited, in accordance with accepted academic practice. No use, distribution or reproduction is permitted which does not comply with these terms. 